\title{
Comparison and analysis of the efficacy of drug therapy for liver cancer
}

\author{
Philippe Merle ${ }^{1,2,3}$, Miroslava Subic ${ }^{1}$ \\ 'Unité d'Hépatologie et Gastroentérologie, Hôpital de la Croix Rousse, Hospices Civils de Lyon, Lyon 69004, France. \\ ${ }^{2}$ Centre de Recherche en Cancérologie de Lyon, INSERM U1052, Lyon 69003, France. \\ ${ }^{3}$ Université Claude Bernard Lyon 1, Villeurbanne 69100, France.
}

Correspondence to: Prof. Philippe Merle, Unité d'Hépatologie, Groupement Hospitalier Lyon Nord, Hospices Civils de Lyon, 103 Grande rue de la Croix-Rousse, Lyon 69004, France. E-mail: philippe.merle@inserm.fr

How to cite this article: Merle P, Subic M. Comparison and analysis of the efficacy of drug therapy for liver cancer. Hepatoma Res 2020;6:60. http://dx.doi.org/10.20517/2394-5079.2020.52

Received: 18 May 2020 First Decision: 24 Jun 2020 Revised: 14 Jul 2020 Accepted: 20 Jul 2020 Published: 1 Sep 2020

Academic Editor: Shu-Kui Qin Copy Editor: Cai-Hong Wang Production Editor: Jing Yu

\begin{abstract}
Hepatocellular carcinoma (HCC) is a poor prognosis tumor when not accessible to potentially curative treatments such as surgical resection, thermal ablations or liver transplantation. Systemic cytotoxic chemotherapies have shown inconsistent clinical benefit. In 2007, sorafenib, a tyrosine kinase inhibitor (TKI), was the first systemic therapy able to significantly improve the outcome of HCC patients non-eligible for curative or loco-regional therapies, despite a modest tolerance and low tumor objective response rate (ORR). Among the newer TKIs approved after 2017, lenvatinib was the first to show a striking ORR and demonstrate non-inferiority vs. sorafenib in the first-line setting. Furthermore, phase 3 trials showed the benefit of other TKIs, regorafenib and cabozantinib, and the anti-angiogenic ramucirumab monoclonal antibody, in systemic second-line therapy. Immune checkpoint inhibitors targeting PD1, achieved striking tumor shrinkage in some patients in monotherapy, seeming to be associated with exciting outcomes. Unfortunately, this occurred in too few patients to improve the median overall survival. More recently, the combination of anti-angiogenic drugs targeting the liver microenvironment with PD-1/ PD-L1 inhibitors, such as the combination of bevacizumab and atezolizumab, proved to be substantially effective in phase 3, and other combinations of PD-1/PD-L1 and CTLA-4 inhibitors or TKIs have raised a lot of hopes for the systemic treatment of HCC.
\end{abstract}

Keywords: Hepatocellular carcinoma, therapy, immune checkpoint inhibitors, tyrosine kinase inhibitors

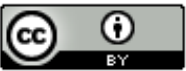

(C) The Author(s) 2020. Open Access This article is licensed under a Creative Commons Attribution 4.0 International License (https://creativecommons.org/licenses/by/4.0/), which permits unrestricted use, sharing, adaptation, distribution and reproduction in any medium or format, for any purpose, even commercially, as long as you give appropriate credit to the original author(s) and the source, provide a link to the Creative Commons license, and indicate if changes were made.

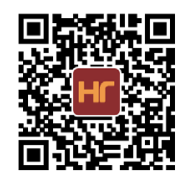




\section{INTRODUCTION}

Hepatocellular carcinoma (HCC) is a poor prognosis tumor ranking fourth as the leading cause of cancer death worldwide, with about 841,000 new cases and 782,000 deaths annually inventoried in $2018^{[1]}$. Due to the frequently silent clinical character and the low sensitivity of currently available diagnostic biomarkers, HCC is commonly diagnosed at an advanced stage when curative treatments, i.e., surgical resection, ablations, and liver transplantation, or radiologic palliative loco-regional therapies are not feasible. Thus, these patients are eligible for systemic strategies ${ }^{[2]}$. Until 2007, treatment options for advanced HCC were lacking. No systemic cytotoxic chemotherapies, including new compounds loaded onto nanoparticles ${ }^{[3]}$, have ever shown to significantly improve overall survival (OS) of HCC patients. Similarly, hormonotherapy and somatostatin analogs have failed to definitely benefit $\mathrm{OS}^{[2]}$. The approval in 2007 of the first oral tyrosine kinase inhibitor (TKI) and antiangiogenic agent (AAA), sorafenib, and the more recent development of other TKIs and immune checkpoint inhibitors (ICIs) as well, have completely revolutionized the therapeutic paradigm for HCC. The perspectives for advanced HCC patients have changed from palliative short-term mortality towards long-term survival expectations. Several drugs are now available, and in this review, we will compare their efficacy with respect to OS and other surrogate endpoints as well, keeping in mind that they are still controversial and their pertinence must be carefully discussed. We will only focus on data emerging from positive phase 3 trials, and from those phase $1 \mathrm{~b} / 2$ studies that led to an early US-FDA approval.

\section{EFFICACY OF DRUGS: ENDPOINTS OF CLINICAL TRIALS}

Clinical trials in HCC have been originally designed according to conventional biostatistical rules applied in oncology trials ${ }^{[4]}$, following the traditional linear model of cancer drug development in which drug activity assessment occurs in randomized confirmatory phase 2 and 3 clinical trials with OS as the most important endpoint for demonstrating clinical benefit. Nevertheless, OS has some disadvantages such as the requirement for long follow-up time, the need for a high number of patients and the possibility to be affected by sequential therapies administrated after tumor progression. The need to achieve a more rapid development of new targeted antitumor agents led to the adoption of innovative clinical trial designs and the identification of surrogate endpoints of survival such as progression-free survival (PFS), time to progression (TTP) and objective response rate (ORR).

\section{Objective response rate}

ORR directly reflects the treatment antitumor activity and is usually defined as the sum of complete (CR) and partial response (PR) rates. In HCC, ORR is measured according to Recist (Response Evaluation Criteria In Solid Tumors) version and/or liver modified-Recist (mRecist) criteria $^{[5]}$. ORR has been considered to be the primary endpoint for phase 2 studies dealing with local ablations or loco-regional therapies studies in HCC where this endpoint is consistently associated with $\mathrm{OS}^{[6]}$. Whereas with the introduction of molecularly targeted treatments with TKIs, reliance on ORR needs to be reconsidered because clinically significant survival advantages are reported despite faint ORRs. Of course, long-lasting stable disease with the absence of progression is a beneficial characteristic, as death due to progression would not occur. In contrast, ORR has shown to be a potentially promising endpoint to obtain clinical benefit from some systemic drugs and in particular ICIs in $\mathrm{HCC}^{[7,8]}$.

Although Recist 1.1 and mRecist criteria can both be used to assess ORR in HCC, Recist 1.1 remains the gold-standard in phase 3 trials with systemic therapies. Of course, it is quite simple to apply Recist 1.1 after liver resection or transplantation. In contrast, local thermoablations or loco-regional intra-arterial therapies induce tumor necrosis, and thus, Recist 1.1 is not appropriate any more since it is unable to capture such an effect since relying on size reduction and ignoring necrosis. That is the reason why the EASL introduced criteria including the use of absence of contrast uptake in dynamic imaging to register response ${ }^{[9]}$, 
Table 1. Objective response rate per Recist 1.1 and/or mRecist

\begin{tabular}{|c|c|c|c|c|c|c|}
\hline & $\begin{array}{l}\text { Led to } \\
\text { committee } \\
\text { approval }\end{array}$ & $\begin{array}{l}\text { Systemic } \\
\text { line }\end{array}$ & $\begin{array}{l}\text { ORR (\%) } \\
(95 \% \mathrm{Cl})\end{array}$ & $\begin{array}{l}\text { Median duration of } \\
\text { response in months } \\
(95 \% \mathrm{Cl})\end{array}$ & DCR (\%) & $\begin{array}{l}\text { First author } \\
\text { (TRIAL) }\end{array}$ \\
\hline $\begin{array}{l}\text { Sorafenib } \\
\text { (vs. placebo) }\end{array}$ & US-FDA, EMA & $1 \mathrm{~L}$ & $\begin{array}{l}\text { IRF Recist } 1.1 \\
2 \%\end{array}$ & ND & $\begin{array}{l}\text { IRF Recist } 1.1 \\
71 \%\end{array}$ & $\begin{array}{l}\text { Llovet et al. }{ }^{[10]} \\
(\mathrm{Ph} 3, \mathrm{SHARP})\end{array}$ \\
\hline $\begin{array}{l}\text { Lenvatinib } \\
\text { (vs. sorafenib) }\end{array}$ & US-FDA, EMA & $1 \mathrm{~L}$ & $\begin{array}{l}\text { IRF Recist 1.1 } \\
\text { 18.8\% (15.3-22.3) } \\
\text { vs.6.5\% (4.3-8.7) } \\
\text { IRF mRecist } \\
40.6 \%(36.2-44) \\
\text { vs.12.4\% (9.4-15.4) }\end{array}$ & ND & $\begin{array}{l}\text { IRF Recist } 1.1 \\
72.8 \%(68.8-76.8) \text { vs. } \\
59.0 \%(54.6-63.5) \\
\text { IRF mRecist } \\
73.8 \%(69.9-77.8) v s . \\
58.4 \%(54.0-62.8)\end{array}$ & $\begin{array}{l}\text { Kudo et al. }{ }^{[11]} \\
\text { (Ph 3, REFLECT) }\end{array}$ \\
\hline $\begin{array}{l}\text { Regorafenib } \\
\text { (vs. placebo) }\end{array}$ & US-FDA, EMA & $2 \mathrm{~L}$ & $\begin{array}{l}\text { Per investigator } \\
\text { Recist } 1.1 \\
7 \%\end{array}$ & $\begin{array}{l}\text { Per investigator } \\
\text { mRecist } \\
3.5(1.9-4.5)\end{array}$ & $\begin{array}{l}\text { Per investigator Recist } \\
1.1 \\
66 \%\end{array}$ & $\begin{array}{l}\text { Bruix et al. }{ }^{[12]} \\
\text { (Ph 3, RESORCE) }\end{array}$ \\
\hline $\begin{array}{l}\text { Cabozantinib } \\
\text { (vs. placebo) }\end{array}$ & US-FDA, EMA & $2 \mathrm{~L}$ or $3 \mathrm{~L}$ & $\begin{array}{l}\text { Per investigator } \\
\text { Recist } 1.1 \\
4 \%\end{array}$ & ND & $\begin{array}{l}\text { Per investigator Recist } \\
1.1 \\
64 \%\end{array}$ & $\begin{array}{l}\text { Abou-Alfa et al. }{ }^{[13]} \\
(\mathrm{Ph} 3, \text { CELESTIAL) }\end{array}$ \\
\hline $\begin{array}{l}\text { Ramucirumab } \\
\text { (vs. placebo) }\end{array}$ & US-FDA, EMA & $2 \mathrm{~L}$ & $\begin{array}{l}\text { Per investigator } \\
\text { Recist } 1.1 \\
5 \%\end{array}$ & $\begin{array}{l}\text { Per investigator Recist } \\
1.1 \\
\text { at } 6 \text { months } \\
59.9 \%\end{array}$ & ND & $\begin{array}{l}\text { Zhu et al. }{ }^{[14]} \\
\text { (Ph 3, REACH-2) }\end{array}$ \\
\hline Nivolumab & US-FDA & $1 \mathrm{~L}$ or $2 \mathrm{~L}$ & $\begin{array}{l}\text { Per investigator } \\
\text { Recist } 1.1 \\
19 \%\end{array}$ & $\begin{array}{l}\text { Per investigator Recist } \\
1.1 \\
9.9 \text { months (8.3-NE) }\end{array}$ & $\begin{array}{l}\text { Per investigator Recist } \\
1.1 \\
64 \%\end{array}$ & $\begin{array}{l}\text { El-Khoueiry et al. }{ }^{[19]} \\
\text { (Ph 1/2, } \\
\text { CheckMate-040, dose- } \\
\text { expansion phase) }\end{array}$ \\
\hline $\begin{array}{l}\text { Nivolumab } \\
\text { (vs. sorafenib) }\end{array}$ & - & $1 \mathrm{~L}$ & $\begin{array}{l}\text { IRF Recist } 1.1 \\
15 \%\end{array}$ & $\begin{array}{l}\text { IRF Recist } 1.1 \\
23.3(3.1-34.5+) v s . \\
23.4(1.9+-28.7+)\end{array}$ & $\begin{array}{l}\text { IRF Recist } 1.1 \\
55 \% \text { vs. } 55 \%\end{array}$ & $\begin{array}{l}\text { Yau et al. }{ }^{[20]} \\
\text { (Ph 3, CheckMate-459) }\end{array}$ \\
\hline Pembrolizumab & US-FDA & $2 \mathrm{~L}$ & $\begin{array}{l}\text { IRF mRecist } \\
17 \%(11-26)\end{array}$ & $\begin{array}{l}\text { IRF mRecist } \\
\text { NR }(3.1-14.6+)\end{array}$ & $\begin{array}{l}\text { IRF mRecist } \\
61 \%\end{array}$ & $\begin{array}{l}\text { Zhu et al. }{ }^{[17]} \\
\text { (Ph 2, KEYNOTE-224) }\end{array}$ \\
\hline $\begin{array}{l}\text { Pembrolizumab } \\
\text { (vs. placebo) }\end{array}$ & - & $2 \mathrm{~L}$ & $\begin{array}{l}\text { IRF Recist } 1.1 \\
18.3 \%(14-23.4)\end{array}$ & $\begin{array}{l}\text { IRF Recist } 1.1 \\
13.8(1.5+-23.6+)\end{array}$ & $\begin{array}{l}\text { IRF Recist } 1.1 \\
62.2 \%\end{array}$ & $\begin{array}{l}\text { Finn et al. }{ }^{[18]} \\
(\mathrm{Ph} 3, \text { KEYNOTE-240) }\end{array}$ \\
\hline $\begin{array}{l}\text { Atezolizumab } \\
+ \text { bevacizumab } \\
\text { (vs. sorafenib) }\end{array}$ & $\begin{array}{l}\text { Ongoing for } \\
\text { US-FDA and } \\
\text { EMA }\end{array}$ & $1 \mathrm{~L}$ & $\begin{array}{l}\text { IRF Recist } 1.1 \\
27 \%(23-33) \\
\text { IRF mRecist } \\
33 \%(28-39)\end{array}$ & $\begin{array}{l}\text { IRF Recist } 1.1 \\
\text { NR } \\
\text { IRF mRecist } \\
\text { NR }\end{array}$ & $\begin{array}{l}\text { IRF Recist } 1.1 \\
74 \% \\
\text { IRF mRecist } \\
72 \%\end{array}$ & $\begin{array}{l}\text { Finn et al/ }{ }^{[16]} \\
(\mathrm{Ph} 3, \text { IMbrave150) }\end{array}$ \\
\hline $\begin{array}{l}\text { Nivolumab } \\
+ \text { ipilimumab }\end{array}$ & US-FDA & $2 \mathrm{~L}$ & $\begin{array}{l}\text { IRF Recist } 1.1 \\
32 \%\end{array}$ & $\begin{array}{l}\text { IRF Recist } 1.1 \\
17.5(4.6-30.5+)\end{array}$ & $\begin{array}{l}\text { IRF Recist } 1.1 \\
50 \%\end{array}$ & $\begin{array}{l}\text { Yau et al. }{ }^{[8]} \\
\text { (Ph 1/2 CheckMate-040, } \\
\text { Arm A) }\end{array}$ \\
\hline
\end{tabular}

US-FDA: American Federal Drug Administration; EMA: European Medicines Agency; NR: not reached; NE: not estimable; ND: not determined; ORR: objective response rate; CR: complete response; PR: partial response; SD: stable disease; DCR: disease control rates: $\mathrm{CR}+\mathrm{PR}+\mathrm{SD}$; IRF: independent review facility; First (1L), second (2L) or third (3L) systemic therapeutic line; Ph: phase

which corresponds to mRecist criteria. If Recist 1.1 can miss the initial antitumor effect on HCC such as devascularization, no study has definitely demonstrated its correlation with OS. Antiangiogenic agents may prompt a variable degree of vascular shutdown - i.e., sorafenib, regorafenib, cabozantinib, ramucirumab and have marginal impact in terms of response as per Recist $1.1^{[10-14]}$.

Further, another issue comes from the inter-observer variability in tumor response assessment per Recist 1.1 and mRecist for HCC. However, although it remains poorly known and warrants prospective assessment, it is possible that concordance is good between operators with expertise in liver imaging and lower with nonspecifically trained operator, independently of the response criteria ${ }^{[15]}$.

As detailed in Table 1, in ORR assessed by Recist 1.1, atezolizumab/bevacizumab ${ }^{[16]}$ and nivolumab/

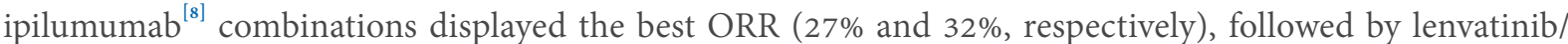
TKI $(18.8 \%)^{[11]}$, ICI monotherapy with pembrolizumab $(17 \%-18.3 \%)^{[17,18]}$ and nivolumab $(15 \%-19 \%)^{[19,20]}$, and at a disappointing lower level all the remaining TKIs such as sorafenib $(2 \%-6.5 \%)^{[10,11]}$, regorafenib $(7 \%)^{[12]}$ and cabozantinib $(4 \%)^{[13]}$, and finally the monoclonal antibody ramucirumab $(5 \%)^{[14]}$. These data suggest that these latter drugs have mostly a tumor-static rather than tumoricidal activity by comparison to the 


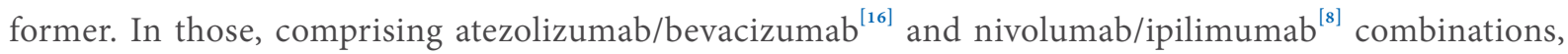
durations of response were long-lasting (median not reached and 17.5 months, respectively) as well as with ICI monotherapies (median 23.3 months with nivolumab ${ }^{[20]}, 13.8$ months with pembrolizumab ${ }^{[18]}$ ), and unfortunately not determined with lenvatinib ${ }^{[11]}$.

ORR might be a surrogate endpoint of drug efficacy in some cases. In phase $1 / 2$ trials with ICIs, ORR by Recist 1.1 seemed to deeply correlate with OS of patients treated either with nivolumab monotherapy ${ }^{[7]}$ or with the nivolumab/ipilimumab combination ${ }^{[8]}$. In both cases, tumor responders (CR + PR) had the best OS [median non-reached (NE-NE) for both cases]. Patients in progression disease (PD) did not seem to have any benefit on OS by comparison to well known patients randomized in the placebo arms in controlled trials [8.9 months (7.3-13.4) and 8.3 months (6.6-10.8), respectively]. Intermediately, stable diseases (SD) had better but not striking data [16.7 (13.8-20.2) and 14.5 (8.4-29.6), respectively]. However, it has not been assessed so far in the atezolizumab/bevacizumab phase 3 trial $^{[16]}$ or other kind of ICI plus AAA combination in phase $1 / 2$ studies, whether ORR has the same predictive value on the outcome of HCC patients. Furthermore, no data on the field are available regarding the correlation between ORR by mRecist and OS of HCC patients treated with ICIs.

These observations do not seem so evident with TKIs, which have the disadvantage of resulting in very low levels of ORR except for lenvatinib ${ }^{[11]}$. ORR (and TTP) have been suggested as potential surrogate endpoints for OS in advanced HCC with brivanib ${ }^{[21,22]}$, and seemed to be confirmed with sorafenib and lenvatinib in REFLECT ${ }^{[11,23]}$. However, a weak correlation was reported between ORR, TTP/PFS and OS in SHARP with sorafenib ${ }^{[10]}$, and with regorafenib in RESORCE ${ }^{[12,24]}$. In this later study, since ORR was rather low either by Recist 1.1 (2\%) or mRecist (10\%), a bootstrap approach was applied to simulate 10,000 trials of patients with advanced HCC from RESORCE $(n=573)$, and the mean simulated results were calculated. A Pearson correlation was calculated between estimated median OS and estimated ORR for regorafenib and placebo arms separately. The Pearson correlation of log-rank test statistics was calculated comparing regorafenib and placebo. The Pearson correlation of log-rank test statistics comparing the two arms for OS was used and the Cochran-Mantel-Haenszel test statistic used to compare the two treatment arms for ORR. Finally, a weak correlation between median OS and ORR was found for regorafenib and placebo in RESORCE, indicating that mRecist/Recist 1.1 ORR may not be a reliable surrogate endpoint for OS in patients with advanced HCC. The same observation was found for TTP in this study.

In summary, ORR could be as a good surrogate marker for OS in HCC patients under lenvatinib or ICI therapy, which give high levels of ORR, whereas it is more complex, debatable and doubtful for drugs with low level of ORR such as sorafenib and regorafenib, keeping in mind that this research has not been performed so far for cabozantinib and ramucirumab.

\section{Progression-free survivals and/or time to radiologic progression}

In HCC, progression-free survival (PFS) is frequently used in phase 2 trials. PFS is a composite endpoint that includes: (1) radiologic progression as defined by Recist 1.1 or mRecist; and (2) death due to tumor progression or the terminal natural history of the underlying chronic liver disease. In general, regulatory agencies prefer PFS to TTP for drug approval because the former endpoint may be better correlated with $\mathrm{OS}^{[25]}$. However, in HCC, PFS might not be reliable because death resulting from the natural history of cirrhosis might confound the detection of potential benefits from effective drugs. The risk of bias in detection of potential benefits from effective antitumor drugs due to death related to liver failure despite a relevant antitumor response can be avoided using restrictive inclusion criteria for evaluation of liver function ${ }^{[25]}$.

Time to radiologic progression (TTP), on the other hand, is a pure radiologic endpoint ${ }^{[26]}$, and requires repeated radiologic measurements to capture relevant differences between groups that can be missed if the 
Table 2. Median PFS and/or TTP following Recist 1.1 and/or mRecist

\begin{tabular}{|c|c|c|c|}
\hline & PFS in months $(95 \% \mathrm{Cl})$ & TTP in months $(95 \% \mathrm{Cl})$ & Authors (Trial) \\
\hline $\begin{array}{l}\text { Sorafenib } \\
\text { vs. placebo }\end{array}$ & ND & $\begin{array}{l}\text { IRF Recist } 1.1 \\
5.5 \text { vs. } 2.8 ; \\
\text { HR }=0.58,95 \% \text { Cl: } 0.45-0.74 ; P< \\
0.001\end{array}$ & $\begin{array}{l}\text { Llovet et al. }{ }^{[10]} \\
(\mathrm{Ph} 3, \mathrm{SHARP})\end{array}$ \\
\hline $\begin{array}{l}\text { Lenvatinib } \\
\text { vs. sorafenib }\end{array}$ & $\begin{array}{l}\text { IRF Recist } 1.1 \\
7.3 \text { vs. } 3.6 \\
\text { HR }=0.65,95 \% \text { Cl: } 0.56-0.77 ; P< \\
0.0001 \\
\text { IRF mRecist } \\
7.3 \text { vs. } 3.6 \\
\text { HR }=0.64,95 \% \text { Cl: } 0.55-0.75 ; P< \\
0.0001\end{array}$ & $\begin{array}{l}\text { IRF Recist } 1.1 \\
7.4 \text { vs. } 3.7 \\
\text { HR }=0.61,95 \% \text { Cl: } 0.51-0.72 ; \\
P<0.0001 \\
\text { IRF mRecist } \\
7.4 \text { vs. } 3.7 \\
\text { HR }=0.60,95 \% \text { Cl: } 0.51-0.71 ; P< \\
0.0001\end{array}$ & $\begin{array}{l}\text { Kudo et al. }{ }^{[11]} \\
\text { (Ph 3, REFLECT) }\end{array}$ \\
\hline \multirow[t]{2}{*}{$\begin{array}{l}\text { Regorafenib } \\
\text { vs. placebo }\end{array}$} & $\begin{array}{l}\text { Per investigator Recist } 1.1 \\
3.4 \text { vs. } 1.5 \\
\text { HR }=0.43,95 \% \mathrm{Cl}: 0.35-0.52 ; P< \\
0.0001\end{array}$ & $\begin{array}{l}\text { Per investigator Recist } 1.1 \\
3.9 \text { vs. } 1.5 \\
\text { HR }=0.41,95 \% \mathrm{Cl}: 0.34-0.51 ; P< \\
0.0001\end{array}$ & $\begin{array}{l}\text { Bruix et al. }{ }^{[12]} \\
\text { (Ph 3, RESORCE) }\end{array}$ \\
\hline & $\begin{array}{l}\text { Per investigator mRecist } \\
3.1 \text { vs. } 1.5 \\
\mathrm{HR}=0.46,95 \% \mathrm{Cl}: 0.37-0.56 ; P< \\
0.0001\end{array}$ & $\begin{array}{l}\text { Per investigator mRecist } \\
3.2 \text { vs. } 1.5 \\
\text { HR }=0.44,95 \% \mathrm{Cl}: 0.36-0.55 ; P< \\
0.0001\end{array}$ & \\
\hline $\begin{array}{l}\text { Cabozantinib } \\
\text { vs. placebo }\end{array}$ & $\begin{array}{l}\text { Per investigator Recist } 1.1 \\
5.2 \text { vs. } 1.9 \\
\mathrm{HR}=0.44,95 \% \mathrm{Cl}: 0.36-0.52 ; P< \\
0.001\end{array}$ & ND & $\begin{array}{l}\text { Abou-Alfa et al/ }{ }^{[13]} \\
\text { (Ph 3, CELESTIAL) }\end{array}$ \\
\hline $\begin{array}{l}\text { Ramucirumab } \\
\text { vs. placebo }\end{array}$ & $\begin{array}{l}\text { Per investigator Recist } 1.1 \\
2.8 \text { vs. } 1.5 \\
\mathrm{HR}=0.57,95 \% \mathrm{Cl}: 0.47-0.69 ; P< \\
0.0001\end{array}$ & ND & $\begin{array}{l}\text { Zhu et al }{ }^{[14]} \\
\text { (Ph 3, REACH-2) }\end{array}$ \\
\hline Nivolumab & $\begin{array}{l}\text { Per investigator Recist } 1.1 \\
4.0(2.9-5.4)\end{array}$ & ND & $\begin{array}{l}\text { El-Khoueiry et al. } .^{[19]} \\
\text { (Ph } 1 / 2 \text {, CheckMate-040, dose- } \\
\text { expansion phase) }\end{array}$ \\
\hline $\begin{array}{l}\text { Nivolumab } \\
\text { vs. sorafenib }\end{array}$ & $\begin{array}{l}\text { Per investigator Recist } 1.1 \\
3.7 \text { vs. } 3.8 \\
\mathrm{HR}=0.93,95 \% \mathrm{Cl}: 0.79-1.10\end{array}$ & ND & $\begin{array}{l}\text { Yau et al. }{ }^{[20]} \\
\text { (Ph 3, CheckMate-459) }\end{array}$ \\
\hline Pembrolizumab & $\begin{array}{l}\text { IRF mRecist } \\
4.9(3.4-7.2)\end{array}$ & $\begin{array}{l}\text { IRF mRecist } \\
4.9(3.9-8.0)\end{array}$ & $\begin{array}{l}\text { Zhu et al. }{ }^{[17]} \\
(\mathrm{Ph} 2, \mathrm{KEYNOTE}-224)\end{array}$ \\
\hline $\begin{array}{l}\text { Pembrolizumab } \\
\text { vs. placebo }\end{array}$ & $\begin{array}{l}\text { IRF Recist } 1.1 \\
3.0 \text { vs. } 2.8 \\
\mathrm{HR}=0.72,95 \% \mathrm{Cl}: 0.57-0.90 ; P= \\
0.0022\end{array}$ & $\begin{array}{l}\text { IRF Recist } 1.1 \\
3.8 \text { vs. } 2.8 \\
\mathrm{HR}=0.69,95 \% \mathrm{Cl}: 0.54-0.87 ; P= \\
0.0011\end{array}$ & $\begin{array}{l}\text { Finn et al. }{ }^{[18]} \\
\text { (Ph 3, KEYNOTE-240) }\end{array}$ \\
\hline $\begin{array}{l}\text { Atezolizumab } \\
+ \text { bevacizumab } \\
\text { vs. sorafenib }\end{array}$ & $\begin{array}{l}\text { IRF Recist } 1.1 \\
6.8 \text { vs. } 4.3 \\
\mathrm{HR}=0.59,95 \% \mathrm{Cl}: 0.47-0.76 ; P< \\
0.0001\end{array}$ & ND & $\begin{array}{l}\text { Finn et al. } .^{[16]} \\
\text { (Ph 3, IMbrave150) }\end{array}$ \\
\hline $\begin{array}{l}\text { Nivolumab } \\
+ \text { ipilimumab }\end{array}$ & ND & ND & $\begin{array}{l}\text { Yau et al }{ }^{[8]} \\
\text { (Ph } 1 / 2 \text { CheckMate-040, Arm A) }\end{array}$ \\
\hline
\end{tabular}

PFS: progression-free survival; TTP: time to radiologic progression; IRF: independent review facility; ND: not determined

intervals between measurements are too long. Symmetric assessment should be ensured between treatment arms. TTP can be recommended as the main time-to-event endpoint to capture possible antitumor benefits in phase 2 trials testing systemic therapies in HCC because it is less vulnerable (only progression is captured) than composite endpoints. However, TTP has been measured less commonly than PFS in HCC phase 3 studies.

In the present review, PFS has been assessed in 7 out of 8 phase 3 studies, and TTP in only 4 of them [Table 2]. When both were available, a close correlation existed between PFS and TTP, thus suggesting that the drugs tested in those trials were not toxic enough to engender death independently of tumor radiologic progression. Taking into account PFS only, atezolizumab/bevacizumab combination clearly gave the best PFS (6.8 months) ${ }^{[16]}$ as well as lenvatinib (7.3 months) ${ }^{[11]}$, although comparison of PFS between trials should 
be done with considerable cautioun. However, the long duration of tumor response under atezolizumab/ bevacizumab combination as discussed above in "ORR" paragraph, was clearly of huge importance to impact on the long median OS (not reached) ${ }^{[16]}$, whereas the quite similar PFS under lenvatinib was associated with a much lower OS (13.6 months $)^{[11]}$. Unfortunately, the duration of response under lenvatinib has not been assessed, although it is likely shorter than under ICIs and similar to those of other TKIs [Table 1], for instance 3.5 months with regorafenib ${ }^{[12]}$. This difference in OS cannot be explained by the disease control rate (DCR by Recist 1.1) since very similar in both trials ( $74 \%$ for atezolizumab/bevacizumab ${ }^{[16]} v \mathcal{s}$. $72.8 \%$ for lenvatinib $\left.{ }^{[11]}\right)$ [Table 1].

PFS by Recist 1.1 for monotherapies of ICI gave values around 4 months $(3.0-4.9)^{[17-20]}$, quite similar to those of TKIs such as sorafenib (3.6 months) $)^{[11]}$ and regorafenib (3.4 months) $)^{[12]}$. PFS seems to be better with cabozantinib (5.2 months $)^{[13]}$, but worse with ramucirumab (2.8 months $)^{[14]}$, which supported a poor prognosis subpopulation. When available, TTP was in accordance with PFS. It is important to underline that ICI monotherapy responders have a long duration of response [Table 1], but the number of responders was too low in the trials to have a significant impact on median PFS or median TTP, and finally on median OS. Differences on PFS/TTP/OS cannot be explained by different DCRs [Table 1] since they were quite the same between ICI and TKI schedules: atezolizumab/bevacizumab $(74 \%)^{[16]}$, nivolumab/ipililumab $(50 \%)^{[8]}$, nivolumab $(55 \%-64 \%)^{[19,20]}$, pembrolizumab $(61 \%-62.2 \%)^{[17,18]}$, lenvatinib $(72.8 \%)^{[11]}$, sorafenib $(59-71 \%)^{[10,11]}$, regorafenib $(66 \%)^{[12]}$, and cabozantinib $(64 \%)^{[13]}$.

\section{Overall survival}

Overall survival (OS), defined as the time from randomization to death, is a direct measure of clinical benefit to a patient and the gold standard primary endpoint to evaluate the outcome in oncologic clinical trials. OS is easily measured, unambiguous, objective, not subjected to researcher bias and it is used by the international authorities worldwide for cancer drug approval. OS is the primary endpoint recommended for all phase 3 studies in HCC. When selecting endpoints in HCC clinical trials, it must be also considered that OS is impacted by liver failure due to both the end stage natural history of underlying chronic liver disease and the HCC loco-regional spread, which in turn promotes liver failure and leads to death. Thus, if the treatment aims to reduce HCC-related death (i.e., the endpoint is cancer-related death), but the competing mortality from progressive liver failure is high in both the active treatment and in the control arms, the risk ratio will be reduced and the required sample size increases. Thus, phase 3 studies in HCC require a larger sample size to include competing risk analysis and assess cancer-related deaths as compared to OS evaluation.

In the present review, regarding OS [Table 3] and taking into account potential confounding factors that may influence the median OS, atezolizumab/bevacizumab therapy has not reached median OS so far taking into account that the median follow-up is only 17 months ${ }^{[16]}$, the nivolumab/ipilimumab combination (22 months $)^{[8]}$, nivolumab (16.4 months $)^{[20]}$, pembrolizumab (12.9-13.9 months $)^{[17,18]}$, lenvatinib (13.6 months $)^{[11]}$, sorafenib (10.7 months $)^{[10]}$, regorafenib (10.6 months) ${ }^{[12]}$ and cabozantinib (10.2 months $)^{[13]}$, while worse with ramucirumab ( 8.5 months) due to the poor prognosis assessed subpopulation ${ }^{[14]}$. The $1 \mathrm{~L}$ or $2 \mathrm{~L}$ design of the trials does not impact much the spontaneous OS of patients since in the placebo arms of randomized controlled trials, median OS is quite the same in $1 \mathrm{~L}$ or $2 \mathrm{~L}$ for HCC patients eligible for systemic therapies with ECOG PS status 0-1 and Child-Pugh A liver functions. Indeed, OS of placebo arms seems similar in $1 \mathrm{~L}$ phase 3 trials $\left(7.9\right.$ months in $\mathrm{SHARP}^{[10]}, 8.5$ months in SEARCH ${ }^{[27]}$ ) by comparison to $2 \mathrm{~L} / 3 \mathrm{~L}$ phase 3 trials (7.9 months in RESORCE ${ }^{[12]}$, 8 months in CELESTIAL ${ }^{[13]}$, 10.6 months in KEYNOTE-240 ${ }^{[18]}$, 8.2 months in BRISK-PS ${ }^{[21]}, 7.3$ months in EVOLVE-1 ${ }^{[28]}, 7.6$ months in $\mathrm{REACH}^{[29]}$, and 9.1 months in METIV$\mathrm{HCC}^{[30]}$.

The control arm and subsequent therapies administered after trial withdrawal are of prominent importance. Indeed, OS in HCC randomized controlled trials depends on the target population, the parameters assessed 
Table 3. Median overall survival

\begin{tabular}{|c|c|c|c|}
\hline & $\begin{array}{l}\text { OS in months } \\
(95 \% \mathrm{Cl})\end{array}$ & Subsequent systemic therapy after trial withdrawal & $\begin{array}{c}\text { Authors } \\
\text { (Trial) }\end{array}$ \\
\hline $\begin{array}{l}\text { Sorafenib } \\
\text { vs. placebo }\end{array}$ & $\begin{array}{l}10.7 \text { vs. } 7.9 \\
\mathrm{HR}=0.69,95 \% \mathrm{Cl}: 0.55-0.87 ; P< \\
0.001\end{array}$ & Absence of active drug against $\mathrm{HCC}$ & $\begin{array}{l}\text { Llovet et } a /_{.}^{[10]} \\
\text { (SHARP) }\end{array}$ \\
\hline $\begin{array}{l}\text { Lenvatinib } \\
\text { vs. sorafenib }\end{array}$ & $\begin{array}{l}13.6 \text { vs. } 12.3 \\
\mathrm{HR}=0.92,95 \% \mathrm{Cl}: 0.79-1.06 \\
\text { meeting criteria for non-inferiority }\end{array}$ & $\begin{array}{l}32.6 \% \text { (sorafenib } 25 \% \text {; investigational therapy) } \\
\text { vs. } \\
38.7 \% \text { (sorafenib 12\%; investigational therapy) }\end{array}$ & $\begin{array}{l}\text { Kudo et al. }{ }^{[11]} \\
\text { (Ph 3, REFLECT) }\end{array}$ \\
\hline $\begin{array}{l}\text { Regorafenib } \\
\text { vs. placebo }\end{array}$ & $\begin{array}{l}10.6 \text { vs. } 7.8 \\
\mathrm{HR}=0.63,95 \% \mathrm{Cl}: 0.50-0.79 ; P< \\
0.0001\end{array}$ & ND & $\begin{array}{l}\text { Bruix et al. }{ }^{[12]} \\
\text { (Ph 3, RESORCE) }\end{array}$ \\
\hline $\begin{array}{l}\text { Cabozantinib } \\
\text { vs. placebo }\end{array}$ & $\begin{array}{l}10.2 \text { vs. } 8.0 \\
\mathrm{HR}=0.76,95 \% \mathrm{Cl}: 0.63-0.92 ; P= \\
0.005\end{array}$ & $\begin{array}{l}25 \% \text { [anti-PD1/PD-L1 5\%; TKI (sorafenib, lenvatinib, } \\
\text { regorafenib) 6.5\%; systemic chemotherapy 12\%; } \\
\text { investigational agents 6\%] } \\
\text { vs. } \\
30 \% \text { [anti-PD1/PD-L1 6\%; TKI (sorafenib, lenvatinib, } \\
\text { regorafenib) 3\%; systemic chemotherapy 17\%; } \\
\text { investigational agents 7\%] }\end{array}$ & $\begin{array}{l}\text { Abou-Alfa et al. }{ }^{[13]} \\
\text { (Ph 3, CELESTIAL) }\end{array}$ \\
\hline $\begin{array}{l}\text { Ramucirumab } \\
\text { vs. placebo }\end{array}$ & $\begin{array}{l}8.1 \text { vs. } 5.0 \\
\mathrm{HR}=0.69,95 \% \mathrm{Cl}: 0.57-0.84 ; P= \\
0.0002\end{array}$ & $\begin{array}{l}26.9 \% \text { [immunotherapy } 6.6 \% \text {; TKI (regorafenib, } \\
\text { sorafenib, cabozantinib, BLU-554, lenvatinib) } 13.7 \% \text {; } \\
\text { systemic chemotherapy } 11.2 \% \text {; investigational drug } \\
2.5 \% \text {; other } 0.5 \% \text { ] } \\
\text { vs. } \\
28.4 \% \text { [immunotherapy } 6.3 \% \text {; TKI (regorafenib, } \\
\text { sorafenib, cabozantinib, BLU-554, lenvatinib) } 6.3 \% \text {; } \\
\text { systemic chemotherapy } 15.8 \% \text {; investigational drug } \\
2.1 \% \text {; other } 1.1 \% \text { ] }\end{array}$ & $\begin{array}{l}\text { Zhu et al. }{ }^{[14]} \\
\text { (Ph 3, REACH-2) }\end{array}$ \\
\hline Nivolumab & NR & ND & $\begin{array}{l}\text { El-Khoueiry et al/ }{ }^{[19]} \\
\text { (Ph 1/2, CheckMate-040, } \\
\text { dose-expansion phase) }\end{array}$ \\
\hline $\begin{array}{l}\text { Nivolumab } \\
\text { vs. sorafenib }\end{array}$ & $\begin{array}{l}16.4 \text { vs. } 14.7 \\
\mathrm{HR}=0.85,95 \% \mathrm{Cl}: 0.72-1.02 ; P= \\
0.0752\end{array}$ & $\begin{array}{l}\text { 49\% (ICI 2\%; TKI 36\%; systemic chemotherapy 4\%; } \\
\text { investigational agent 3\%; other 1\%) } \\
\text { vs. } \\
53 \% \text { (ICI 20\%; TKI 23\%; systemic chemotherapy } \\
7 \% \text {; investigational agent 11\%; other 1\%) }\end{array}$ & $\begin{array}{l}\text { Yau et al. }{ }^{[20]} \\
\text { (Ph 3, CheckMate-459) }\end{array}$ \\
\hline Pembrolizumab & $\begin{array}{l}12.9 \\
(95 \% \mathrm{Cl}: 9.7-15.5)\end{array}$ & ND & $\begin{array}{l}\text { Zhu et al. }{ }^{[17]} \\
\text { (Ph 2, KEYNOTE-224) }\end{array}$ \\
\hline $\begin{array}{l}\text { Pembrolizumab } \\
\text { vs. placebo }\end{array}$ & $\begin{array}{l}13.9 \text { vs. } 10.6 \\
\mathrm{HR}=0.78,95 \% \mathrm{Cl}: 0.61-0.99 ; P= \\
0.0238\end{array}$ & $\begin{array}{l}41.7 \% \text { [approved anticancer medication } 31.7 \%: \mathrm{ICl} \\
6.8 \% \text {, others (lenvatinib, regorafenib, ramucirumab) } \\
31.7 \% \text { ] } \\
\text { vs. } \\
47.4 \% \text { [approved anticancer medication } 31.9 \%, \mathrm{ICl} \\
10.4 \% \text {, others (lenvatinib, regorafenib, ramucirumab) } \\
31.9 \% \text { ] }\end{array}$ & $\begin{array}{l}\text { Finn et al. }{ }^{[18]} \\
(\text { Ph 3, KEYNOTE-240) }\end{array}$ \\
\hline $\begin{array}{l}\text { Atezolizumab } \\
+ \text { bevacizumab } \\
\text { vs. sorafenib }\end{array}$ & $\begin{array}{l}\text { NR vs. } 13.2 \\
\mathrm{HR}=0.58,95 \% \mathrm{Cl}: 0.42-0.79 \\
P=0.0006\end{array}$ & ND & $\begin{array}{l}\text { Finn et al. }{ }^{[16]} \\
\text { (Ph 3, IMbrave150) }\end{array}$ \\
\hline $\begin{array}{l}\text { Nivolumab } \\
+ \text { ipilimumab }\end{array}$ & $\begin{array}{l}22.8 \\
(95 \% \mathrm{Cl}: 9.4-\mathrm{NE})\end{array}$ & ND & $\begin{array}{l}\text { Yau et al } .^{[8]} \\
(\text { Ph } 1 / 2 \text { CheckMate-040, } \\
\text { Arm A) }\end{array}$ \\
\hline
\end{tabular}

OS: overall survival; NR: not reached; NE: not evaluable; ND: not determined; TKI: tyrosine kinase inhibitor; ICI: immune checkpoint inhibitor

and reported in the trial, the stratification before randomization in both the active and the control arms. For most HCC trials, the study population is composed of approximately $80 \%$ BCLC-C and 20\% BCLC-B HCCs, with a good general status (PS ECOG 0-1) and conserved liver functions (Child-Pugh A). A critical element that can substantially affect the interpretation of trial results is whether patients are allowed to receive medications or undergo procedures potentially active against HCC after trial withdrawal.

As far as control arms are considered, the SHARP trial ${ }^{[10]}$ still represents a paradigm since patients were treated in both arms up to symptomatic progression, and patients could not be treated by other active drugs after radiologic progression since such drugs were not existing [Table 3]. Thus, in SHARP, OS of the control arm (composed of placebo only or subsequent inactive drugs against HCC) was 7.9 months, and sorafenib 
increased OS vs. placebo with a hazard ratio (HR) of 0.69 (95\%CI: $0.55-0.87, P<0.0001)^{[10]}$. REFLECT was a head-to-head comparison of lenvatinib and sorafenib, within a non-inferiority trial ${ }^{[11]}$, but after trial withdrawal, $33 \%$ and $39 \%$ of patients received potentially active medications against HCC, likely one of the reasons why the OS of sorafenib improved from SHARP (10.7 months) conducted a couple of years before $2008^{[10]}$, towards REFLECT (12.3 months) conducted 10 years later ${ }^{[11]}$ [Table 3]. In the other 1 L systemic therapies with control arm, the same comments can arise from CheckMate-459 comparing nivolumab to sorafenib ${ }^{[20]}$. It was an open label trial, and at radiologic progression, patients were withdrawn and received potentially active subsequent medications [Table 3]. That explains, at least in part, the high OS value in the sorafenib arm (14.7 months), that maybe led to conceal the benefit of nivolumab (OS 16.4 months) vs. sorafenib (HR 0.85 [95\%CI: 0.72-1.02]; $P=0.0752)^{[20]}$. The same conclusions can be drawn from the IMBrave150 trial ${ }^{[16]}$ [Table 3] where OS under sorafenib was surprisingly high at 13.2 months, and the atezolizumab/bevacizumab combination increased OS (not reached) vs. sorafenib (13.2 months) with HR of 0.58 (95\% CI $0.42-0.79, P<0.0006)^{[16]}$, the efficacy of the atezolizumab/bevacizumab combination being high enough to prevent any concealing by the overestimated value of OS in the sorafenib arm.

\section{However, operator experience acquired over time is also likely a relevant factor that has a greater impact on OS in the sorafenib arms}

In $2 \mathrm{~L}$ setting, all control arms were placebo arms, also debatable due to post-withdrawal medications [Table 3]. In spite of the overestimated values of OS in placebo arms in $2 \mathrm{~L}$, regorafenib increased OS with $\mathrm{HR}$ of 0.63 (95\%CI: 0.50-0.79, $P<0.0001)^{[12]}$, cabozantinib improved OS with HR of $0.76(95 \% \mathrm{CI} 0.63-0.92, P<0.005)^{[13]}$, and ramucirumab improved OS with HR of 0.71 (95\%CI: 0.53-0.95, $P=0.0199)^{[14]}$. In the KEYNOTE-240 phase 3 study, the trial did not meet the statistical criteria for either of the dual endpoints (OS and PFS) although pembrolizumab improved OS over placebo with HR of $0.78(95 \% \text { CI } 0.61-0.99, P=0.0238)^{[18]}$, but the placebo arm showed abnormally high OS value of 10.6 months, in part due to post-withdrawal trial medication [Table 3].

\section{CONCLUSION}

For more than a decade, huge improvements have arisen in the systemic strategy of HCC therapy. The coming $1 \mathrm{~L}$ will associate atezolizumab and bevacizumab. Of course, a lot a work remains to be done to improve this combination and find some strategies overwhelming primary or secondary resistances. Results are soon expected from other $1 \mathrm{~L}$ combinations in phase 3: pembrolizumab/lenvatinib (NCT03713593), atezolizumab/cabozantinib (NCT03755791), durvalumab/tremelimumab (NCT03298451), and nivolumab/ ipilimumab (NCT 04039607). At the moment, there is also an urgent need for prospective controlled trials to identify the best TKI therapy following progression under any ICI combination schedule. Sorafenib and lenvatinib were the two possible $1 \mathrm{~L}$. Will they remain the gold standard after ICI combination schedule failure? If yes, the subsequent TKIs after their own failure would likely remain regorafenib, cabozantinib or ramucirumab, if not used in the prior ICI combination schedules of $1 \mathrm{~L}$. Only randomized controlled trials will guide the future ways of research and draw the future therapeutic algorithms to improve more and more the treatment of HCC.

\section{DECLARATIONS}

\section{Authors' contributions}

Made substantial contribution to conception and design of the review article, and performed data analysis and interpretation: Merle P, Subic M

\section{Availability of data and materials}

Not applicable. 


\section{Financial support and sponsorship}

None.

\section{Conflicts of interest}

Merle P has to declare AbBoard with Bayer, Ipsen, Exelixis, Eisai, Lilly, Roche, Bristol Myers Squibb, AstraZeneca, and Onxeo. Subic M declared that there are no conflicts of interest.

\section{Ethical approval and consent to participate}

Not applicable.

\section{Consent for publication}

Not applicable.

\section{Copyright}

(C) The Author(s) 2020.

\section{REFERENCES}

1. Bray F, Ferlay J, Soerjomataram I, Siegel RL, Torre LA, et al. Global cancer statistics 2018: GLOBOCAN estimates of incidence and mortality worldwide for 36 cancers in 185 countries. CA Cancer J Clin 2018;68:394-424.

2. Bruix J, Reig M, Sherman M. Evidence-based diagnosis, staging, and treatment of patients with hepatocellular carcinoma. Gastroenterology 2016;150:835-53.

3. Merle P, Blanc J, Phelip J, Pelletier G, Bronowicki J, et al. Doxorubicin-loaded nanoparticles for patients with advanced hepatocellular carcinoma after sorafenib treatment failure (RELIVE): a phase 3 randomised controlled trial. Lancet Gastroenterol Hepatol 2019;4:454-65.

4. Whitehead J. Stopping clinical trials by design. Nat Rev Drug Discov 2004;3:973-7.

5. Vogel A, Cervantes A, Chau I, Daniele B, Llovet J, et al. Hepatocellular carcinoma: ESMO clinical practice guidelines for diagnosis, treatment and follow-up. Ann Oncol 2018;29:iv238-55.

6. Llovet JM, Real MI, Montaña X, Planas R, Coll S, et al. Arterial embolisation or chemoembolisation versus symptomatic treatment in patients with unresectable hepatocellular carcinoma: a randomised controlled trial. Lancet 2002;359:1734-9.

7. El-Khoueiry AB, Melero I, Yau T, Crocenzi TS, Kudo M, et al. Impact of antitumor activity on survival outcomes, and nonconventional benefit, with nivolumab in patients with advanced hepatocellular carcinoma: subanalysis of CheckMate-040. J Clin Oncol 2018;36:475.

8. Yau T, Kang YK, Kim TY, El-Khoueiry AB, Santoro A, et al. Nivolumab + ipilimumab combination therapy in patients with advanced hepatocellular carcinoma: results from CheckMate-040. J Clin Oncol 2019;37:4012.

9. Bruix J, Sherman M, Llovet JM, Beaugrand M, Lencioni R, et al. Clinical management of hepatocellular carcinoma. Conclusions of the Barcelona-2000 EASL Conference. J Hepatol 2001;35:421-30.

10. Llovet JM, Ricci S, Mazzaferro V, Hilgard P, Gane E, et al; SHARP Investigators Study Group. Sorafenib in advanced hepatocellular carcinoma. N Engl J Med 2008;359:378-90.

11. Kudo M, Finn RS, Qin S, Han K, Ikeda K, et al. Lenvatinib versus sorafenib in first-line treatment of patients with unresectable hepatocellular carcinoma: a randomised phase 3 non-inferiority trial. Lancet 2018;391:1163-73.

12. Bruix J, Qin S, Merle P, Granito A, Huang Y, et al. Regorafenib for patients with hepatocellular carcinoma who progressed on sorafenib treatment (RESORCE): a randomised, double-blind, placebo-controlled, phase 3 trial. Lancet 2017;389:56-66.

13. Abou-Alfa GK, Meyer T, Cheng AL, El-Khoueiry AB, Rimassa L, et al. Cabozantinib in patients with advanced and progressing hepatocellular carcinoma. N Engl J Med 2018;379:54-63.

14. Zhu AX, Kang Y, Yen C, Finn RS, Galle PR, et al. Ramucirumab after sorafenib in patients with advanced hepatocellular carcinoma and increased $\alpha$-fetoprotein concentrations (REACH-2): a randomised, double-blind, placebo-controlled, phase 3 trial. Lancet Oncol 2019;20:282-96.

15. Tovoli F, Renzulli M, Negrini G, Brocchi S, Ferrarini A, et al. Inter-operator variability and source of errors in tumour response assessment for hepatocellular carcinoma treated with sorafenib. Eur Radiol 2018;28:3611-20.

16. Finn RS, Qin S, Ikeda M, Galle PR, Ducreux M, et al; IMbrave150 Investigators. Atezolizumab plus bevacizumab in unresectable hepatocellular carcinoma. N Engl J Med 2020;382:1894-905.

17. Zhu AX, Finn RS, Edeline J, Cattan S, Ogasawara S, et al. Pembrolizumab in patients with advanced hepatocellular carcinoma previously treated with sorafenib (KEYNOTE-224): a non-randomised, open-label phase 2 trial. Lancet Oncol 2018;19:940-52.

18. Finn RS, Ryoo BY, Merle P, Kudo M, Bouattour M, et al. Pembrolizumab as second-line therapy in patients with advanced hepatocellular carcinoma in KEYNOTE-240: a randomized, double-blind, phase III trial. J Clin Oncol 2020;38:193-202.

19. El-Khoueiry AB, Sangro B, Yau T, Crocenzi TS, Kudo M, et al. Nivolumab in patients with advanced hepatocellular carcinoma (CheckMate 040): an open-label, non-comparative, phase 1/2 dose escalation and expansion trial. Lancet 2017;389:2492-502.

20. Yau T, Park JW, Finn RS, Cheng AL, Mathurin P, et al. CheckMate 459: a randomized, multi-center phase III study of nivolumab vs 
sorafenib as first-line treatment in patients with advanced hepatocellular carcinoma. Barcelona (Spain): European-Society-for-MedicalOncology (ESMO) Congress; 2019.

21. Llovet JM, Decaens T, Raoul JL, Boucher E, Kudo M, et al. Brivanib in patients with advanced hepatocellular carcinoma who were intolerant to sorafenib or for whom sorafenib failed: results from the randomized phase III BRISK-PS study. J Clin Oncol 2013;31:3509-16.

22. Lencioni R, Montal R, Torres F, Park JW, Decaens T, et al. Objective response by mRECIST as a predictor and potential surrogate endpoint of overall survival in advanced HCC. J Hepatol 2017;66:1166-72.

23. Kudo M, Finn RS, Qin SK, Han KH, Ikeda K, et al. Analysis of survival and objective response in patients with hepatocellular carcinoma in a phase III study of lenvatinib (REFLECT). San Francisco: Gastrointestinal Cancers Symposium (ASCO GI) Congress; 2019.

24. Bruix J, Huang LP, Nakajima K, Han GH, Meinhardt G, et al. Time to progression and response rate are not reliable surrogate endpoints for overall survival in hepatocellular carcinoma: an analysis from the phase 3 RESORCE trial. San Francisco: American Association for the Study of Liver Diseases (AASLD) Congress; 2018.

25. Llovet JM, Montal R, Villanueva A. Randomized trials and endpoints in advanced HCC: role of PFS as a surrogate of survival. J Hepatol 2019;70:1262-77.

26. Miller AB, Hoogstraten B, Staquet M, Winkler A. Reporting results of cancer treatment. Cancer 1981;47:207-14.

27. Zhu AX, Rosmorduc O, Evans TR, Ross PJ, Santoro A, et al. SEARCH: a phase III, randomized, double-blind, placebo-controlled trial of sorafenib plus erlotinib in patients with advanced hepatocellular carcinoma. J Clin Oncol 2015;33:559-66.

28. Zhu AX, Kudo M, Assenat E, Cattan S, Kang YK, et al. Effect of everolimus on survival in advanced hepatocellular carcinoma after failure of sorafenib: the EVOLVE-1 randomized clinical trial. JAMA 2014;312:57-67.

29. Zhu AX, Baron AD, Malfertheiner P, Kudo M, Kawazoe S, et al. Ramucirumab as second-line treatment in patients with advanced hepatocellular carcinoma: analysis of REACH trial results by child-pugh score. JAMA Oncol 2017;3:235-43.

30. Rimassa L, Assenat E, Peck-radosavljevic M, Pracht M, Zagonel V, et al. Tivantinib for second-line treatment of MET-high, advanced hepatocellular carcinoma (METIV-HCC): a final analysis of a phase 3, randomised, placebo-controlled study. Lancet Oncol 2018;19:682-93. 